\title{
Design of New Au-NiCo MEMS Vertical Probe for Fine-Pitch Wafer-Level Probing
}

\author{
Xuan Luc Le $(1)$ and Sung-Hoon Choa * \\ Graduate School of Nano IT Design Fusion, Seoul National University of Science and Technology, \\ Seoul 01811, Korea; Xuanluc.bkahn@gmail.com \\ * Correspondence: shchoa@seoultech.ac.kr
}

Citation: Le, X.L.; Choa, S.-H. Design of New Au-NiCo MEMS Vertical Probe for Fine-Pitch Wafer-Level Probing. Crystals 2021, 11, 485. https://doi.org/10.3390/ cryst11050485

Academic Editor: Ji-Hoon Lee

Received: 22 March 2021

Accepted: 24 April 2021

Published: 26 April 2021

Publisher's Note: MDPI stays neutral with regard to jurisdictional claims in published maps and institutional affiliations.

Copyright: (c) 2021 by the authors. Licensee MDPI, Basel, Switzerland. This article is an open access article distributed under the terms and conditions of the Creative Commons Attribution (CC BY) license (https:/ / creativecommons.org/licenses/by/ $4.0 /)$.

\begin{abstract}
As fine-pitch 3D wafer-level packaging becomes more popular in semiconductor industries, wafer-level prebond testing of various interconnect structures has become increasingly challenging. Additionally, improving the current-carrying capacity (CCC) and minimizing damage to the probe and micro-interconnect structures are very important issues in wafer-level testing. In this study, we propose an $\mathrm{Au}-\mathrm{NiCo}$ MEMS vertical probe with an enhanced CCC to efficiently reduce the damage to the probe and various interconnect structures, including a solder ball, $\mathrm{Cu}$ pillar microbump, and TSV. The Au-NiCo probe has an Au layer inside the NiCo and an Au layer outside the surface of the NiCo probe to reduce resistivity and contact stress. The current-carrying capacity, contact stress, and deformation behavior of the probe and various interconnect structures were evaluated using numerical analyses. The Au-NiCo probe had a 150\% higher CCC than the conventional NiCo probe. The maximum allowable current capacity of the $5000 \mu \mathrm{m}$-long $\mathrm{Au}-\mathrm{NiCo}$ probe was $750 \mathrm{~mA}$. The $\mathrm{Au}-\mathrm{NiCo}$ probe exhibited less contact force and stress than the NiCo probe. The Au-NiCo probe also produced less deformation of various interconnect structures. These results indicate that the proposed $\mathrm{Au}-\mathrm{NiCo}$ probe will be a prospective candidate for advanced wafer-level testing, with better probing efficiency and higher test yield and reliability than the conventional vertical probe.
\end{abstract}

Keywords: vertical probe; current-carrying capacity; contact force; deformation; numerical analysis

\section{Introduction}

Three-dimensional (3D) wafer-level packaging (WLP) is a mainstream advanced packaging technology to meet the various requirements of semiconductor industries, including low cost, low profile, high input/output (I/O), high electrical performances, and high reliability [1,2]. Advanced wafer-level packaging, such as fan-out wafer-level packaging (FOWLP) technology [3,4] and panel-level packaging (PLP) [5], have attracted recent attraction because they provide several advantages, including high $\mathrm{I} / \mathrm{O}$, low cost because they eliminate the substrate, and better thermal performance. Among advanced packaging technologies, various 3D integration or interconnection technologies have also been developed, such as through-silicon vias (TSVs) [6], microbumps [7], and solder-capped pillar microbumps [8]. Wafer testing is an important stage in the integrated circuit manufacturing and packaging process. Selective die testing and sorting are mandatory processes, used to check that each chip on the wafer meets good electrical signal transmission standards [9]. In particular, a wafer testing before the bonding process, known as a prebond test, is commonly required to enhance the test yield in 3D WLP [10]. Wafer testing on these advanced packages is more difficult because they have unique, weaker, and more complex interconnect structures than the conventional flat metal electrode on the wafer. Vertical probes, also known as "cobra"-type probes, have been widely used for this wafer-level packaging test [11].

To meet the demands of high density (or fine pitch) wafer-level probing, the probe should be narrow and slender. A long probe has more advantages than a short probe in 
wafer-level probing. First, a long probe, which uses a buckling phenomenon, guarantees consistent contact pressure and can compensate for the unevenness of arrayed structures such as microsolder balls and copper $(\mathrm{Cu})$ pillar microbumps $[12,13]$. Second, the buckling probe has lower contact force, since the probe tip acts as a spring, reducing the contact force between the probe tip and arrayed interconnect structures. This minimizes damage and deformation of the solder balls and microbumps, as well as the probe tip. Excessive probe marks or damage of the probe will also influence the test efficiency, test yield, lifespan of the probe, subsequent fabrication or assembly process, and the reliability of the packaging $[14,15]$. However, a long probe has lower current-carrying capacity (CCC) than a short probe. The current-carrying capacity of the probe is a very important parameter, to ensure enough current is provided for IC chip testing. Presently, more than 1 A current is required for wafer testing [16]. However, when the electrical current passes through the probe, it will heat the probe, and the probe's temperature will increase due to the Joule-heating (or $\mathrm{I}^{2} \mathrm{R}$ heating) effect. The resistance of the probe tip depends on the length, cross-sectional area, and material characteristics of the probe [16]. The longer and slenderer the probe, the higher the resistance. Excessive heating will cause changes in the physical properties and mechanical behavior of the probe, and eventually lead to the probe burning or melting $[9,16]$. For these reasons, highly elastic and robust materials such as $\mathrm{Ni}-\mathrm{Co}$, tungsten, $\mathrm{Be}-\mathrm{Cu}$, and Paliney are commonly used to fabricate the vertical probe $[9,16,17]$. However, these materials have high resistivity. To enhance the probe's current-carrying capacity and lifespan, and to minimize damage to various interconnect structures, it is necessary to optimize the probe's structural design and materials. Notably, in wafer-level testing, the MEMS vertical probe has many outstanding advantages such as fine pitch, high probe density, high speed, and high uniformity [17-20].

In this study, we propose a novel design for a MEMS vertical probe for wafer-level testing, to improve its current-carrying capacity and minimize damage to various interconnect structures, including solder balls, Cu pillar microbumps, and TSV structures. The new microelectromechanical (MEMS) vertical probe design is based on the conventional $\mathrm{NiCo}$ vertical probe. Gold ( $\mathrm{Au}$ ) material was applied inside and outside of the NiCo probe to reduce electrical resistivity and high contact stress, respectively. To evaluate the CCC of the probes, a numerical thermal-electrical analysis was conducted, with a heat-transfer analysis. Contact behavior such as deformation, contact force, and the stress of the probe and various interconnect structures with different overdrives (OD) were numerically analyzed.

\section{Numerical Modeling and Analysis}

Figure 1a shows a geometric model of the MEMS vertical probe, which consisted of two guide plates and the probe. The vertical probe was a kind of cobra-type square probe. The probe had a curved profile in the middle with a radius of $2250 \mu \mathrm{m}$ during the touchdown process. The length and width of the probe were $2500 \mu \mathrm{m}$ and $30 \mu \mathrm{m}$, respectively. A horizontal offset of $800 \mu \mathrm{m}$ was applied to the probe during contact. The thickness of the guide plate was $200 \mu \mathrm{m}$. Figure $1 \mathrm{~b}$ shows a schematic drawing of the probe's behavior when in contact with a solder ball. The solder ball on the wafer moved upward along the z-axis to contact the probe. During contact, the probe was bent due to the guide plates, acting like a spring. This movement reduced the contact force of the probe contacting the solder ball $[9,11]$. The gap between the guide plate hole and probe was $1 \mu \mathrm{m}$. This gap was small enough to keep the motion of the probe along the z-axis without lateral displacement along the $x$ and $y$ axes. The guide was made of ceramic and considered to be a rigid body. 


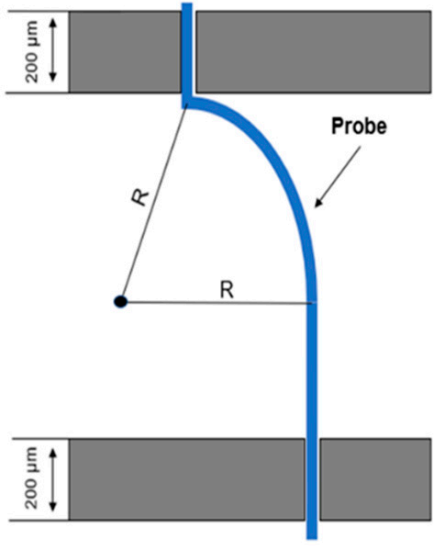

(a)

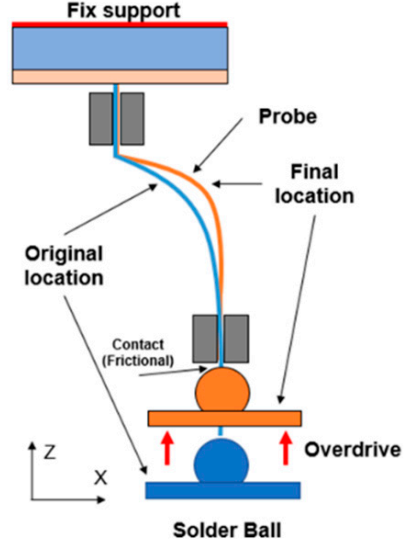

(b)

Figure 1. (a) Geometric model of the MEMS vertical probe. (b) Schematic drawing of the behavior of the vertical probe in contact with a solder ball.

Figure 2 exhibits schematic drawings of the cross-sections of two types of probes. Figure 2a shows a NiCo probe with a fillet of $6 \mu \mathrm{m}$ at the edge of the probe tip. Figure $2 \mathrm{~b}$ exhibits the proposed $\mathrm{Au}-\mathrm{NiCo}$ probe design. The $\mathrm{Au}-\mathrm{NiCo}$ probe had an $\mathrm{Au}$ layer inside of the $\mathrm{NiCo}$, and the outside surface was also coated with Au. The thicknesses of the Au layer inside and Au coating outside were $10 \mu \mathrm{m}$ and $2 \mu \mathrm{m}$, respectively. The electrical resistivities of the $\mathrm{Au}$ and NiCo were $2.44 \times 10^{-8} \Omega \times \mathrm{m}$ and $6.9 \times 10^{-8} \Omega \times \mathrm{m}$, respectively, at room temperature (Table 1). Gold has a lower resistivity than NiCo, thus reducing the heat generated by the probe. In this study, we used a Ni-Co alloy composed of $66.2 \% \mathrm{Ni}$ and $33.8 \% \mathrm{Co}$ [21]. The NiCo probe had a Young's modulus of $200 \mathrm{GPa}, \mathrm{a}$ Poisson's ratio of 0.31 , and yield strength of $1876.6 \mathrm{MPa}$. Gold has a Young's modulus of $78 \mathrm{GPa}$, Poisson's ratio of 0.42 , and a yield strength of $117.7 \mathrm{MPa}$.

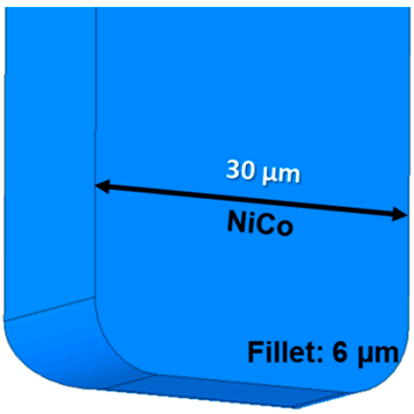

(a)
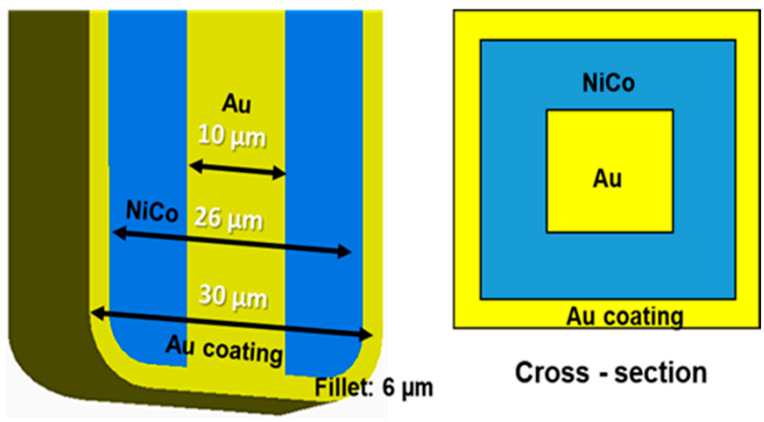

(b)

Figure 2. Schematic drawings of the cross-sections of the two types of probes: (a) NiCo probe; (b) Au-NiCo probe.

Table 1. Properties of materials used in analyses of the current-carrying capacities.

\begin{tabular}{cccccc}
\hline Material & $\begin{array}{c}\text { Resistivity } \\
(\mathbf{n} \Omega \cdot \mathbf{m})\end{array}$ & $\begin{array}{c}\text { Thermal } \\
\text { Conductivity } \\
(\mathbf{W} / \mathbf{m} \cdot \mathbf{K})\end{array}$ & $\begin{array}{c}\text { Specific Heat } \\
(\mathbf{J} / \mathbf{g} \cdot \mathbf{K})\end{array}$ & $\begin{array}{c}\text { Seebeck } \\
\text { Coefficient } \\
(\boldsymbol{\mu} \mathbf{V} / \mathbf{K})\end{array}$ & $\begin{array}{c}\text { Melting } \\
\text { Point } \\
\left({ }^{\circ} \mathbf{C}\right)\end{array}$ \\
\hline $\mathrm{Au}$ & 24.4 & $316\left(\right.$ at $\left.293^{\circ} \mathrm{K}\right)$ & 0.129 & 6.5 & 1064 \\
$\mathrm{NiCo}$ & 69 & $89\left(\right.$ at $\left.293^{\circ} \mathrm{K}\right)$ & 0.44 & -15 & 1455 \\
\hline
\end{tabular}

Note: capacities were determined at room temperature $\left(20^{\circ} \mathrm{C}\right)$.

A numerical simulation of the current-carrying capacities was conducted using a thermo-electrical coupled analysis, which is a type of heat-transfer analysis that considers 
the heat generated by Joule-heating in the probe. A steady-state heat-transfer analysis was conducted. To evaluate the limits of CCC for each probe, a current from 0 to $1000 \mathrm{~mA}$ was applied to the probes. For the thermal boundary condition, natural convection heat transfer was applied. The ambient temperature was $19^{\circ} \mathrm{C}$, and the coefficient of the natural convection at ambient temperature was $9.75 \mathrm{~W} / \mathrm{m}^{2} \mathrm{~K}$ [9]. The thermo-electrical properties of the probes used for the numerical simulation are listed in Table 1, including resistivity, thermal conductivity, and Seebeck coefficient. Gold has a melting point of $1064{ }^{\circ} \mathrm{C}$, and $\mathrm{Ni}-\mathrm{Co}$ has a melting point of $1455^{\circ} \mathrm{C}$. When the temperature of the probe increases to near melting point, it will degrade the mechanical strength of the probe, resulting in both a decrease in contact force and the durability of the probe. Eventually it will lead to the burning or melting of the probe.

We analyzed the deformation behavior and stress of the probes and various interconnect structures, including solder balls, copper pillar microbumps, and TSV structures. Figure 3 provides schematic drawings of the various interconnect structures. Figure $3 a$ shows a Sn-Ag solder ball on the silicon wafer. A Cu under-ball metallization (UBM) layer was deposited beneath the solder ball. The solder ball had a diameter of $60 \mu \mathrm{m}$ and height of $50 \mu \mathrm{m}$. When the probe tip touched the solder ball, the probe tip penetrated into the solder ball, and deformation occurred at the contact area, creating a probe mark. Figure $3 \mathrm{~b}$ shows the structure of a $\mathrm{Cu}$ micropillar bump with a diameter of $50 \mu \mathrm{m}$, height of $50 \mu \mathrm{m}$, and UBM layer. Figure $3 \mathrm{c}$ is the TSV structure with a $\mathrm{Cu}$ via $50 \mu \mathrm{m}$ in diameter, surrounded by a silicon oxide $\left(\mathrm{SiO}_{2}\right)$ layer $1 \mu \mathrm{m}$ thick.

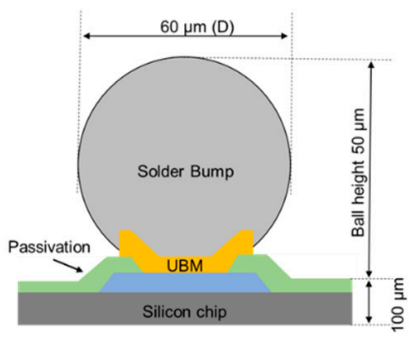

(a)

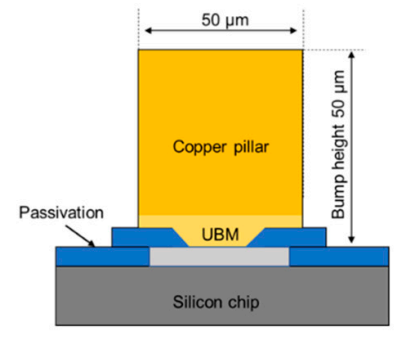

(b)

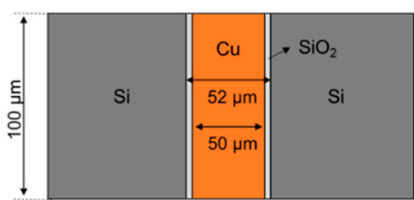

(c)

Figure 3. Schematic drawing of various interconnect structures: (a) solder ball; (b) Copper pillar microbump; (c) through-silicon via structure.

The vertical movement of the probe after the first contact of the probe tip is known as overdrive. The deformation behavior and stress were analyzed as the overdrive was increased up to $150 \mu \mathrm{m}$. Table 2 shows the mechanical properties of the materials used in the numerical simulation. We used typical material property values referenced in several studies [21-23]. During contact, there was friction at the interface between the probe tip and the interconnect structure. The coefficient of friction was assumed to be 0.12 [19]. We assumed that there were no natural oxides formed on the material surfaces of the solder and $\mathrm{Cu}$ microbump in the simulation. 3D modeling was used for the numerical analysis. Because it had a symmetrical structure, a 1/2 model was used to reduce computation time. Figure 4 shows the numerical model of the probe and solder ball. To increase the accuracy of the simulation results, fine mesh was used at the contact point of the probe tip and the interconnect structures. The model had a total of 74,809 nodes and 28,161 elements. ANSYS 2019 numerical software was used to analyze the thermoelectricity, heat transfer, deformation, and stress of the probe and interconnect structures. 
Table 2. Properties of materials used in the mechanical-behavior analyses.

\begin{tabular}{cccccc}
\hline Material & $\begin{array}{c}\text { E } \\
(\mathbf{G P a})\end{array}$ & $\begin{array}{c}\text { Hardness } \\
\mathbf{( H v )}\end{array}$ & $\begin{array}{c}\text { Yield Strength } \\
\mathbf{( M P a )}\end{array}$ & $\boldsymbol{v}$ & $\begin{array}{c}\text { Tangent Modulus } \\
\mathbf{( M P a})\end{array}$ \\
\hline $\mathrm{Ni}-\mathrm{Co}$ & 200 & $482-610$ & 1876.65 & 0.31 & 1000 \\
$\mathrm{Au}$ & 78 & $188-216$ & 117.72 & 0.42 & 500 \\
$\mathrm{Al}$ & 70 & & 35 & 0.34 & 500 \\
$\mathrm{Cu}$ & 120 & & 350 & 0.34 & 500 \\
$\mathrm{Sn}-\mathrm{Ag}$ & 47.5 & & 30 & 0.4 & 500 \\
$\mathrm{Si}$ & 180 & & 7000 & 0.27 & 1000 \\
$\mathrm{SiO}_{2}$ & 66 & & 8400 & 0.17 & 1000 \\
\hline
\end{tabular}

Note: E: Young's modulus; v: Poisson's ratio.

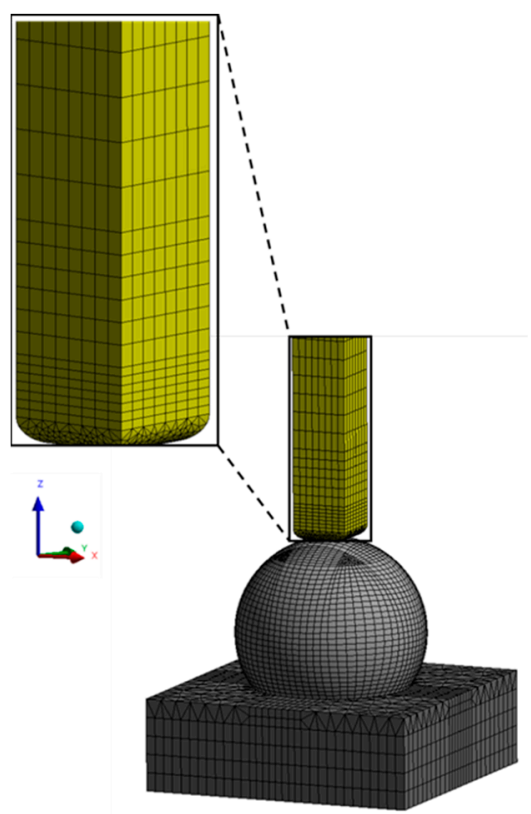

Figure 4. Numerical modeling of the probe and solder ball.

\section{Results and Discussion}

\subsection{Evaluation of Current-Carrying Capacities}

The performance of the probe depended on its ability to carry a sufficient electrical current for the chip (IC) test [9]. When an electrical current was applied to the probe, it would increase the temperature across the entire probe due to the Joule-heating effect. The current-carrying capacity of the probe material depended on the electrical resistivity, the cross-sectional area, the length of the probe, and the applied current [16]. Too high a current level will cause immediate burnout of the probe, or deformation or degradation of the probe. Furthermore, as the electrical current increased and the temperature increased, the thermoelectric properties of the probe changed. In this study, we considered the change of resistivity, thermal conductivity, and specific heat of the materials used to fabricate the probe. Table 1 shows the material properties at room temperature $\left(20{ }^{\circ} \mathrm{C}\right)$. We used the typical temperature-dependent material properties reported in several reference articles [24-27], and applied these properties for numerical simulation of the MEMS vertical probe.

The CCC of the probe was evaluated while increasing the applied current from 0 to $1000 \mathrm{~mA}$ for different probe lengths from 1000 to $5000 \mu \mathrm{m}$. Figure 5a shows the simulation results for the temperature generated when a current of $1000 \mathrm{~mA}$ flowed through the $2500 \mu \mathrm{m}$-long NiCo probe. The highest temperature for each probe always occurred in the middle region of the probe. Figure $5 \mathrm{~b}$ shows the results of the temperature of the NiCo probe with increasing current. When the current of the probe increased, the temperature increased very quickly. When the length of the probe increased, the temperature also 
increased very sharply. For the $1000 \mu \mathrm{m}$-long probe, the maximum temperature generated was $168^{\circ} \mathrm{C}$ at a current of $1000 \mathrm{~mA}$, and this temperature was lower than the melting point of the NiCo material $\left(1455^{\circ} \mathrm{C}\right)$. The temperature increased slowly with increasing current.

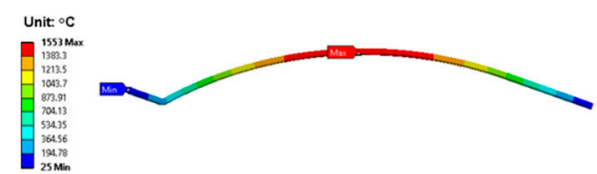

(a)

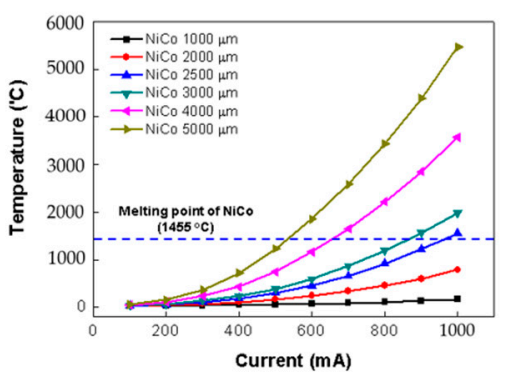

(b)

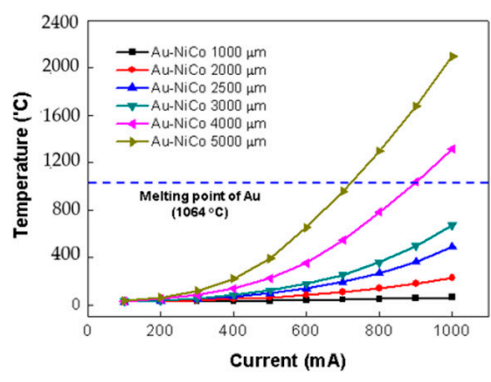

(c)

Figure 5. (a) Simulated distribution of the temperature generated when a current of $1000 \mathrm{~mA}$ flowed through the $2500 \mu \mathrm{m}$-long NiCo probe. (b) Results for temperature of the NiCo probe with increasing current for different probe lengths. (c) Results for temperature of the Au-NiCo probe with increasing current.

When the probe length was $2500 \mu \mathrm{m}$, the maximum temperature generated at $1000 \mathrm{~mA}$ was $1553{ }^{\circ} \mathrm{C}$, which is quite high. At a current of $970 \mathrm{~mA}$, the temperature dropped to $1466^{\circ} \mathrm{C}$, which was still higher than the melting temperature of NiCo. This indicated the allowable current for a $2500 \mu \mathrm{m}$-long probe is less than $970 \mathrm{~mA}$. For a $5000 \mu \mathrm{m}-1$ ong probe, the temperature increased significantly as the current increased. The maximum temperature generated at $1000 \mathrm{~mA}$ was $5459^{\circ} \mathrm{C}$, which is extremely higher than the melting point of NiCo. This probe temperature was nearly 32 times higher than the probe with a length of $1000 \mu \mathrm{m}$. When a current of $550 \mathrm{~mA}$ was applied, the temperature of the probe was $1522{ }^{\circ} \mathrm{C}$, which was still higher than the melting point. Therefore, it is noted that the maximum allowable current of the $5000 \mu \mathrm{m}$-long NiCo probe was less than $500 \mathrm{~mA}$. These results imply that the conventional NiCo probe had a very limited current-carrying capacity when the probe length was more than $5000 \mu \mathrm{m}$.

Therefore, an optimal probe design requires changing the material or structure of the probe to increase the current-carrying capacity. An optimized design will improve the probe's performance for high-current intensive testing purposes. Figure $5 \mathrm{c}$ shows the temperature of the $\mathrm{Au}-\mathrm{NiCo}$ probe. We can see a significant decrease in temperature compared to the NiCo probe. For the $1000 \mu \mathrm{m}$-long probe, the maximum temperature was only $63{ }^{\circ} \mathrm{C}$ at a current of $1000 \mathrm{~mA}$. When the length of the probe was increased to $2500 \mu \mathrm{m}$, the maximum temperature reached $488^{\circ} \mathrm{C}$ at the $1000 \mathrm{~mA}$ current. For the $5000 \mu \mathrm{m}$-long probe, the highest temperature generated was $2095^{\circ} \mathrm{C}$. This temperature was higher than the melting point of $\mathrm{NiCo}\left(\sim 1455^{\circ} \mathrm{C}\right)$ and $\mathrm{Au}\left(\sim 1060^{\circ} \mathrm{C}\right)$. Considering the melting temperature of $\mathrm{Au}$, the maximum allowable current was $750 \mathrm{~mA}$ for the $5000 \mu \mathrm{m}$ long probe. For the $4000 \mu \mathrm{m}$-long probe, the allowable current was less than $900 \mathrm{~mA}$. These results indicated that the proposed $\mathrm{Au}-\mathrm{NiCo}$ probe had a superior current-carrying capacity compared with the conventional vertical probe.

\subsection{Deformation Behavior of the Probe and Interconnect Structures}

The analysis of mechanical deformation and stress is a very important method of optimizing and improving the performance and lifetime of the probe. Fatigue of the probe 
or the deformation of interconnect structures will not lead to immediate failure, but may influence the probing efficiency, postfabrication process, and reliability of the probe and devices. In this study, we investigated the deformation behavior of various interconnect structures including solder balls, Cu pillar microbumps, and TSV using the NiCo probe and $\mathrm{Au}-\mathrm{NiCo}$ probe. Figure 6a exhibits the von Mises stress distribution of the probe tip area of the NiCo probe during contact with a solder ball at an overdrive of $150 \mu \mathrm{m}$. The maximum stress occurred at the center of the probe tip. Figure $6 \mathrm{~b}$ shows the variation in the maximum stress of the $\mathrm{NiCo}$ and $\mathrm{Au}-\mathrm{NiCo}$ probes with increasing overdrive. The probe stress linearly increased with increasing overdrive. However, as the overdrive increased above $40 \mu \mathrm{m}$, the stress increased very slightly because probe buckling took place. When the buckling of the probe occurred, the contact force was reduced significantly. The NiCo probe exhibited a larger stress than the $\mathrm{Au}-\mathrm{NiCo}$ probe. The maximum stresses generated in the NiCo probe and $\mathrm{Au}-\mathrm{NiCo}$ probe were $158 \mathrm{MPa}$ at an overdrive of $150 \mu \mathrm{m}$ and $108 \mathrm{MPa}$ at an overdrive of $60 \mu \mathrm{m}$, respectively. Considering that the yield strength of NiCo and $\mathrm{Au}$ materials were $1876 \mathrm{MPa}$ and $117 \mathrm{MPa}$, respectively, the maximum stress of the NiCo probe tip during contact was lower than the yield strength of the material, therefore it would not cause plastic deformation of the probe or probe wear.

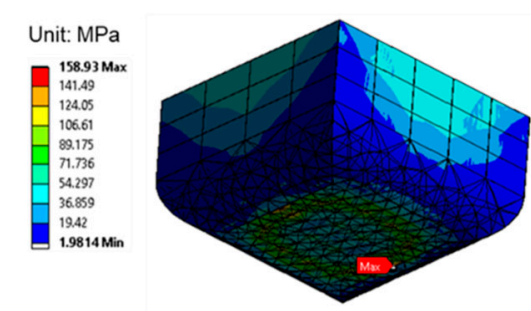

(a)

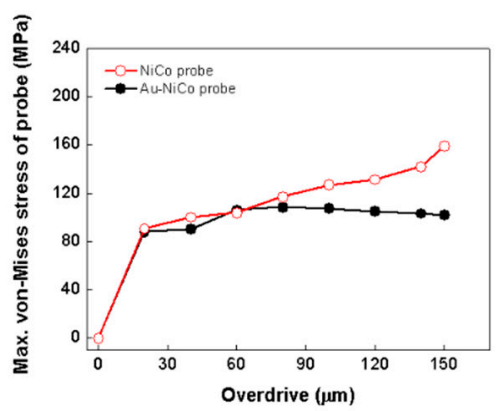

(b)

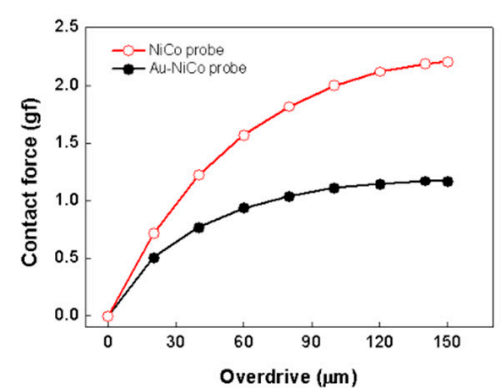

(c)

Figure 6. (a) The von Mises stress distribution map of the NiCo probe tip area during contact with a solder ball. (b) The variation in the maximum stress of the NiCo and $\mathrm{Au}-\mathrm{NiCo}$ probes with increasing overdrive. (c) The variation in the probe contact forces with increasing overdrive.

However, for the $\mathrm{Au}-\mathrm{NiCo}$ probe, the contact stress of the probe was higher than the yield stress of the Au material above an overdrive of $60 \mu \mathrm{m}$. Therefore, it was expected that the $\mathrm{Au}-\mathrm{NiCo}$ probe would likely be vulnerable to fatigue and long-term durability at a large overdrive. Figure $6 c$ shows the contact forces acting on the probe. The contact force also increased with increasing overdrive and became saturated at an overdrive of $120 \mu \mathrm{m}$ due to the buckling phenomenon. The contact force of the NiCo probe was larger than that of the $\mathrm{Au}-\mathrm{NiCo}$ probe. The maximum contact forces at overdrive (OD) $=150 \mu \mathrm{m}$ were $2.2 \mathrm{~g}$ force (gf) and $1.2 \mathrm{gf}$ for the $\mathrm{NiCo}$ probe and $\mathrm{Au}-\mathrm{NiCo}$ probe, respectively.

Figure 7a shows the von Mises stress distribution map on the Sn-Ag solder ball when the probe was in contact with the solder ball. The top area of the solder ball was slightly pressed and deformed. Figure $7 \mathrm{~b}$ exhibits the stress variation in the solder ball with increasing overdrive. The maximum stress on the solder ball increased as the overdrive increased, and became saturated at an overdrive of $40 \mu \mathrm{m}$. In general, the stress level of the 
solder ball using the Au-NiCo probe was slightly lower than when using the NiCo probe. The maximum stresses generated on the solder ball using the $\mathrm{NiCo}$ and $\mathrm{Au}-\mathrm{NiCo}$ probes were 88 and $104 \mathrm{MPa}$, respectively at an overdrive of $150 \mu \mathrm{m}$. This maximum stress level exceeded the yield strength (30 MPa) of the Sn-Ag solder ball, thus causing permanent plastic deformation of the solder ball. Mechanical deformation of the various interconnect structures during probe contact is one of the critical issues affecting probing efficiency, reliability, and subsequent fabrication processes.

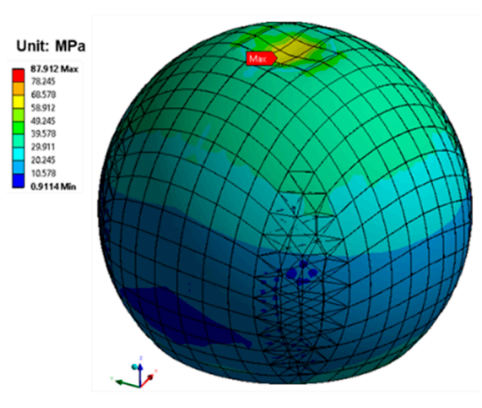

(a)

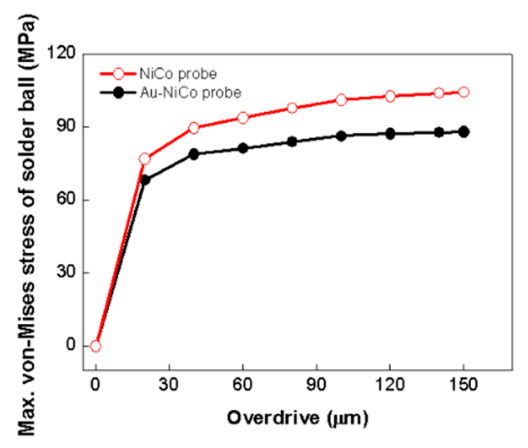

(b)

Figure 7. (a) The von Mises stress distribution map of the solder ball when the probe was in contact with the solder ball. (b) The variation in maximum stress in the solder ball with increasing overdrive.

Figure 8a provides a schematic drawing of the deformation area and deformation depth caused by the probe contact. It is known that the deformation area (or probe mark) on the solder ball should be lower than $25-30 \%$ of the cross-sectional area of the solder ball during contact [11]. Figure $8 \mathrm{~b}$ exhibits the deformation area and deformation ratio (or percent) of the solder ball with increasing overdrive. In the figure, the deformation ratio on the solder ball was defined such that the deformation area was divided by the area of the solder ball $\left(2830 \mu \mathrm{m}^{2}\right)$. The Au-NiCo probe created less deformation on the solder ball than the NiCo probe. At an overdrive of $20 \mu \mathrm{m}$, the deformation ratio of the solder ball was $9 \%$ and $6 \%$ for the NiCo probe and $\mathrm{Au}-\mathrm{NiCo}$ probe, respectively. The deformation area of the solder ball increased linearly with increasing overdrive. At an overdrive of $150 \mu \mathrm{m}$, the solder-ball deformation ratios of the $\mathrm{NiCo}$ probe and $\mathrm{Au}-\mathrm{NiCo}$ probe were $17.1 \%$ and $12.1 \%$, respectively, which were lower than the allowable maximum deformation ratio of $25 \%$. Figure $8 \mathrm{c}$ shows the deformation depth of the solder ball. The deformation depth also increased with increasing overdrive, and the NiCo probe exhibited twice as much deformation as the $\mathrm{Au}-\mathrm{NiCo}$ probe. However, the deformation depth of 1-2 $\mu \mathrm{m}$ was very small compared with the diameter of the solder ball. These results indicated that the $\mathrm{Au}-\mathrm{NiCo}$ probe offered a better probing efficiency and a higher test yield and reliability than the NiCo probe.

Next, we analyzed the deformation behavior of other interconnect structures, including a $\mathrm{Cu}$ pillar microbump and a TSV structure. Figure 9 depicts the variation in contact forces with increasing overdrive when the probe contacted the $\mathrm{Cu}$ micropillar bump. The trend of contact force with overdrive was very similar to that of the solder-ball contact. Figure 10a shows the stress distribution map of the NiCo probe and $\mathrm{Cu}$ microbump at an overdrive of $150 \mu \mathrm{m}$. The maximum stress was located at the outer edge of the probe. Figure $10 \mathrm{~b}$ exhibits the changes in maximum stress generated in the probe for different overdrives. In general, the stress generated in the probe contacting the $\mathrm{Cu}$ microbump was larger than that contacting the solder ball. The stress generated in the Au-NiCo probe was much smaller than that in the NiCo probe. However, the stress level generated in the $\mathrm{Au}-\mathrm{NiCo}$ probe was around 104-113 MPa, which was close to the yield strength of the Au material. 


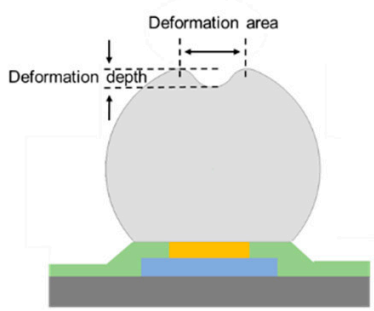

(a)

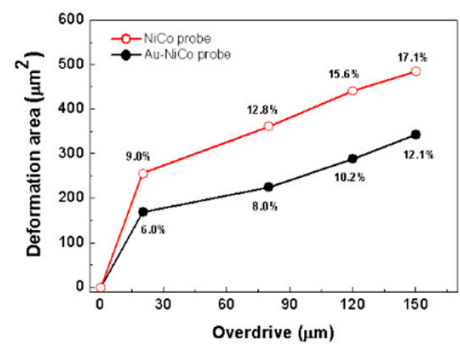

(b)

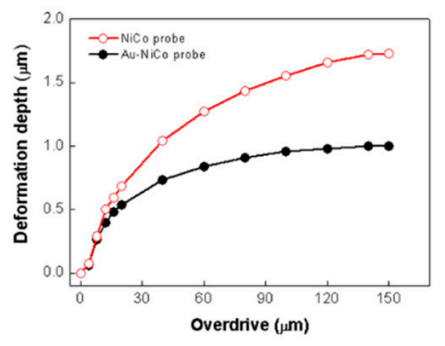

(c)

Figure 8. (a) Schematic drawing of the deformation area and deformation depth caused by the probe contact. (b) Deformation area and deformation ratio of the solder ball with increasing overdrive. (c) Depth of deformation in the solder ball with increasing overdrive.

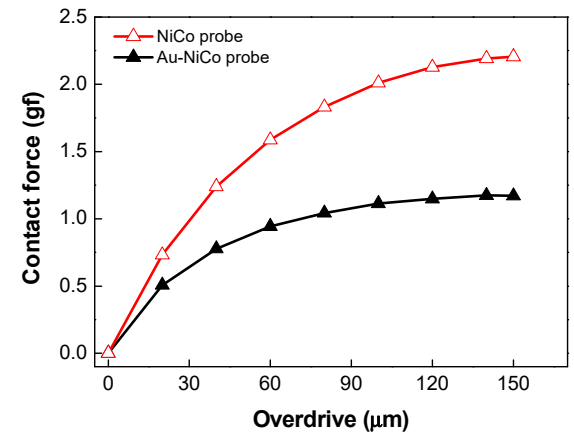

Figure 9. Variation in contact forces with increasing overdrive when the probe contacted the $\mathrm{Cu}$ pillar microbump.
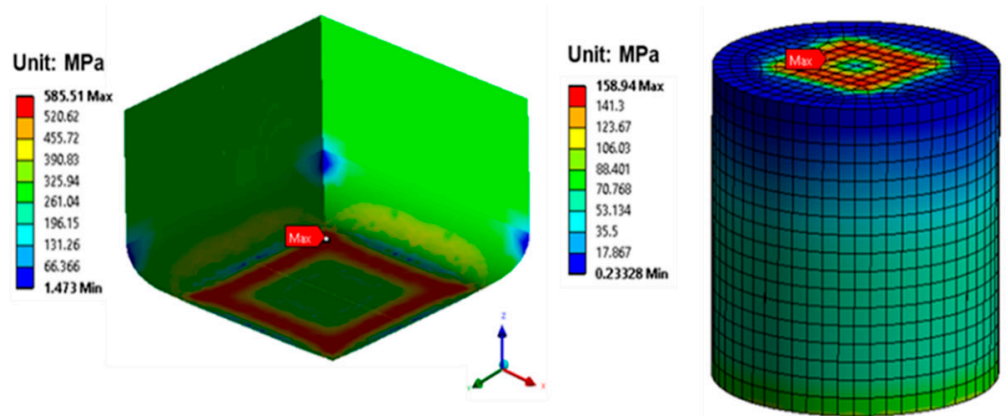

(a)

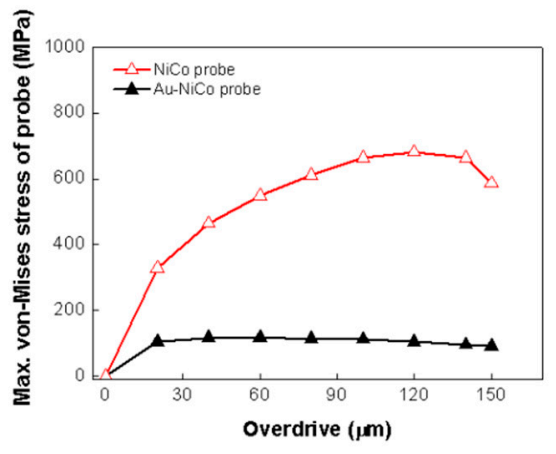

(b)

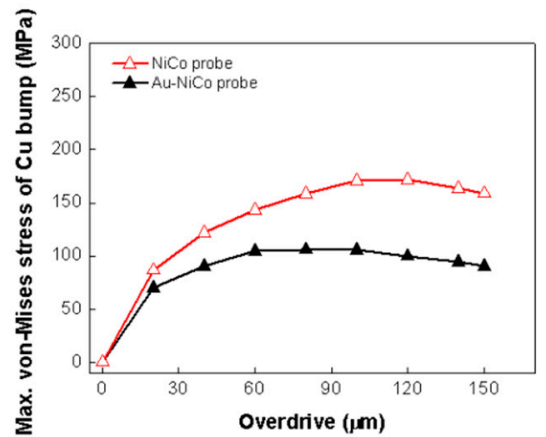

(c)

Figure 10. (a) Stress distribution map of the NiCo probe and Cu microbump at an overdrive of $150 \mu \mathrm{m}$. (b) The variation in the maximum stress generated in the probe for different overdrives. (c) The variation in the maximum stress of the $\mathrm{Cu}$ microbump for different overdrives. 
Figure 10c shows the variation in the maximum stress of the $\mathrm{Cu}$ microbump. The maximum stresses generated in the $\mathrm{Cu}$ microbump using the NiCo probe and $\mathrm{Au}-\mathrm{NiCo}$ probe were $172 \mathrm{MPa}$ and $106 \mathrm{MPa}$, respectively. Considering that the yield strength of copper is around $350 \mathrm{MPa}$, the contact stress was much lower than the yield stress. Therefore, during the contact, the $\mathrm{Cu}$ microbump was not plastically deformed, and the deformation depth of the Cu microbump was very small, less than $1 \mu \mathrm{m}$.

Figure 11 exhibits the variation in contact forces with different overdrives for the TSV structure. The trend in contact forces was almost identical to that of the $\mathrm{Cu}$ pillar microbump probing.

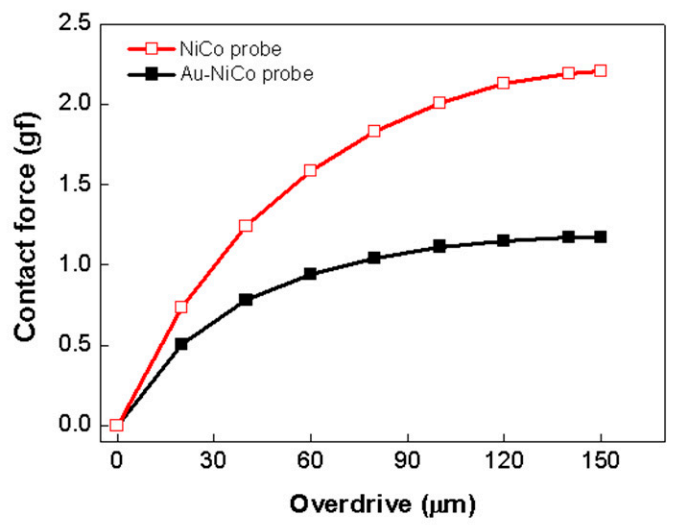

Figure 11. The variation in the contact forces with different overdrives for the TSV structure.

Figure 12a shows the von Mises stress distribution generated in the Cu via of the TSV structures using the NiCo probe at an overdrive of $150 \mu \mathrm{m}$. Figure $12 \mathrm{~b}, \mathrm{c}$ show the variation in the maximum stress generated in the $\mathrm{Cu}$ via and probe, respectively, with increasing overdrive. The trend in stress variation was also similar to the case with the $\mathrm{Cu}$ pillar microbump. However, the stress level in the TSV was much higher than with the Cu pillar microbump. Unlike the $\mathrm{Cu}$ pillar microbump, the $\mathrm{Cu}$ via in the TSV was surrounded by a stiff $\mathrm{SiO}_{2}$ layer and $\mathrm{Si}$ wafer, and the lateral deformation of the $\mathrm{Cu}$ via was restricted by these materials during the probe contact. As a result, the $\mathrm{Cu}$ via was subjected to a higher stress than the $\mathrm{Cu}$ pillar microbump. The maximum stress in the $\mathrm{Cu}$ via was $233 \mathrm{MPa}$ at $\mathrm{OD}=80 \mu \mathrm{m}$ for the NiCo probe, which was still lower than the yield strength of the copper. The stress in the probe was also higher than that of the $\mathrm{Cu}$ pillar microbump. Among the interconnect structures in this study, the probe stress was highest when contacting the TSV via. High stress on the probe tip will cause long-term fatigue and reduce the lifespan of the probe.

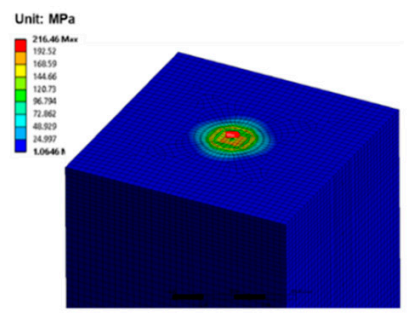

(a)

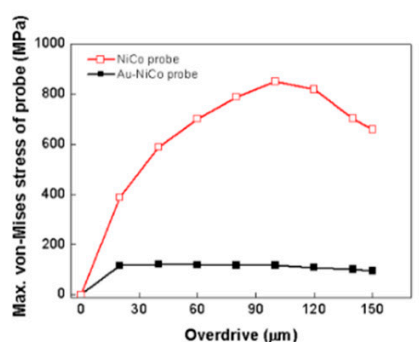

(b)

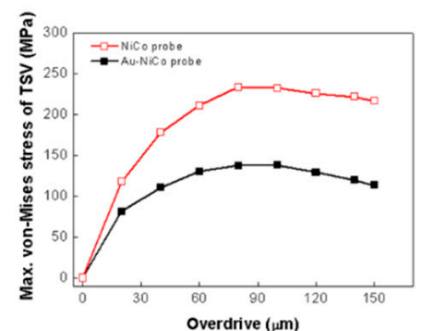

(c)

Figure 12. (a) The von Mises stress distribution generated in the $\mathrm{Cu}$ via of the TSV structure. (b) The variation in the maximum stress generated in the $\mathrm{Cu}$ via with increasing overdrive. (c) The variation in the maximum stress generated in the probe with increasing overdrive. 


\section{Conclusions}

Wafer-level testing of the various interconnect structures used in 3D integration is a new challenge because of their small, weak, and complex structures. In this study, we proposed a novel design of a MEMS vertical probe to improve the probe's currentcarrying capacity and to minimize damage to the probe and various interconnect structures, including a solder ball, $\mathrm{Cu}$ pillar microbump, and TSV structure. The new MEMS vertical $\mathrm{Au}-\mathrm{NiCo}$ probe design was based on the NiCo probe. To reduce probe resistivity and high contact stress, the new vertical probe had an Au-cored layer inside the NiCo probe and an Au coating outside the surface of the NiCo probe. The current-carrying capacity and deformation behavior of the probe and various interconnect structures were analyzed and compared with a conventional NiCo probe using numerical simulations. As the current and length of the probe increased, the temperature of the probe significantly increased. The allowable maximum current capacity of the $5000 \mu \mathrm{m}$-long NiCo probe was less than $500 \mathrm{~mA}$. The maximum allowable current of the $5000 \mu \mathrm{m}$-long $\mathrm{Au}-\mathrm{NiC}$ probe was $750 \mathrm{~mA}$. The $4000 \mu \mathrm{m}$-long $\mathrm{Au}-\mathrm{NiCo}$ probe had an allowable current capacity of $900 \mathrm{~mA}$. The Au$\mathrm{NiCo}$ probe also showed less probe stress and contact force than the NiCo probe. However, the $\mathrm{Au}-\mathrm{NiCo}$ probe will be slightly more vulnerable to fatigue and mechanical durability than the NiCo probe, due to the low yield strength of the $\mathrm{Au}$. The $\mathrm{Au}-\mathrm{NiCo}$ probe also caused less deformation to various interconnect structures, indicating the $\mathrm{Au}-\mathrm{NiCo}$ probe will have better probing efficiency and a higher test yield and reliability than the NiCo probe. Among the interconnect structures, the probe stress was the highest when contacting the TSV structure.

Author Contributions: The manuscript was written using contributions of all authors. All authors have read and agreed to the published version of the manuscript.

Funding: This research was supported by the Ministry of Trade, Industry and Energy (MOTIE), Korea, through the "Development of an integrated (probe/space transformer) $50 \mu \mathrm{m}$ pitch vertical MEMS probe card for highly integrated semiconductors" (grant no. 10080743) and the "Development of probe card technology for fine pitch TSV and FO package test (grant no. 20000874)".

Data Availability Statement: Not applicable.

Conflicts of Interest: The authors declare no conflict of interest.

\section{References}

1. Xu, Z.; Lu, J.Q. Through-Silicon-Via Fabrication Technologies, Passives Extraction, and Electrical Modeling for 3-D Integration/Packaging. IEEE Trans. Semicond. Manuf. 2013, 26, 23-34. [CrossRef]

2. Kim, S.E. Heterogeneous Device Packaging Technology for the Internet of Things Applications. J. Microelectron. Packag. Soc. 2016, 23, 1-6. [CrossRef]

3. Tseng, C.-F.; Liu, C.-S.; Wu, C.-H.; Yu, D. InFO (Wafer Level Integrated Fan-Out) Technology. In Proceedings of the 2016 IEEE 66th Electronic Components and Technology Conference (ECTC), Las Vegas, NV, USA, 31 May-3 June 2016; pp. 1-6.

4. Lee, M.K.; Jeoung, J.W.; Ock, J.Y.; Choa, S.-H. Numerical Analysis of Warpage and Reliability of Fan-out Wafer Level Package. J. Microelectron. Packag. Soc. 2014, 21,31-39. [CrossRef]

5. Lau, J.H. Recent Advances and Trends in Fan-Out Wafer/Panel-Level Packaging. J. Electron. Packag. 2019, 141, 040801. [CrossRef]

6. Gambino, J.P.; Adderly, S.A.; Knickerbocker, J.U. An overview of through-silicon-via technology and manufacturing challenges. Microelectron. Eng. 2015, 135, 73-106. [CrossRef]

7. Li, J.; Zhang, Y.; Zhang, H.; Chen, Z.; Zhou, C.; Liu, X.; Zhu, W. The thermal cycling reliability of copper pillar solder bump in flip chip via thermal compression bonding. Microelectron. Reliab. 2020, 104, 113543. [CrossRef]

8. Sa, Y.-K.; Yoo, S.; Shin, Y.-S.; Han, M.-K.; Lee, C.-W. Joint properties of solder capped copper pillars for 3D packaging. In Proceedings of the 2010 Proceedings 60th Electronic Components and Technology Conference (ECTC), Las Vegas, NV, USA, 1-4 June 2010; pp. 2019-2024.

9. Jung, H.-W.; Kim, S.-J.; Kim, Y.-J.; Kim, J.-Y.; Lee, J.-Y.; Park, J.-H. Finite element analysis of vertical micro-probe considering Joule-heating effect. Int. J. Fatigue 2017, 101, 96-105. [CrossRef]

10. Kim, C.K.; Yoon, Y.H.; Kwon, D.; Kim, S.; Yoon, G.W.; Rhee, M.W.; Yun, J.; Park, I.; Yoon, J.B. First Lateral Contact Probing of 55- $\mu \mathrm{m}$ Fine Pitch Micro-Bumps. J. Microelectromec. Syst. 2018, 27, 1114-1123. [CrossRef]

11. Chang, H.-Y.; Pan, W.-F.; Lin, S.-M. Investigation of Contact Behavior and Design of Vertical Probe for Wafer Level Probing. IEEE Trans. Compon. Packag. Manuf. Technol. 2012, 2, 710-718. [CrossRef] 
12. Chiu, J.-T.; Chang, D.-Y. A new probe design combining finite element method and optimization used for vertical probe card in wafer probing. Precis. Eng. 2009, 33, 395-401. [CrossRef]

13. Hauck, T.; Müller, W. Large deformation of beam columns-A closed form solution and design guide for vertical buckling probe needles. In Proceedings of the 2010 11th International Thermal, Mechanical \& Multi-Physics Simulation, and Experiments in Microelectronics and Microsystems (EuroSimE), Bordeaux, France, 26-28 April 2010; pp. 1-3. [CrossRef]

14. Brezmes, A.O.; Breitkopf, C. Mechanical analysis of wafer testing with FEM simulations. Microelectron. Reliab. 2016, 63, 166-182. [CrossRef]

15. Hill, L.W.; Blaylock, N.L.; Hunter, S. Finite Element Modeling and Characterization of Cantilever Probe Tips Used in Wafer Test. In Proceedings of the IEEE Semiconductor Wafer Test Workshop, San Diego, CA, USA, 8-11 June 2014.

16. Zafer, B.; Tunaboylu, B. A predictive model for wafer probe burn phenomenon. Appl. Therm. Eng. 2016, 98, 610-616. [CrossRef]

17. Hsiao, T.-C.; Huang, S.-C.; Chang, H.-Y. Design optimization of vertical needle geometry for bump wafer-level probing. Trans. Can. Soc. Mech. Eng. 2017, 41, 313-326. [CrossRef]

18. Tunaboylu, B. Testing of Copper Pillar Bumps for Wafer Sort. IEEE Trans. Compon. Packag. Manuf. Technol. 2011, 2, 985-993. [CrossRef]

19. Kwon, H.-J.; Lee, J.; Shin, B.; Jeon, S.; Han, C.S.; Im, C.M. Geometry design of vertical probe needle using mechanical testing and finite element analysis. Int. J. Precis. Eng. Manuf. 2014, 15, 2335-2342. [CrossRef]

20. Shin, B.; Kwon, H.-J.; Han, S.-W.; Im, C.M. Fatigue life estimation of vertical probe needle for wafer probing. Int. J. Precis. Eng. Manuf. 2015, 16, 2509-2515. [CrossRef]

21. Park, J.-H.; Chun, Y.-B.; Kim, Y.-J.; Huh, Y.-H.; Kang, D.-J. Tensile and high cycle fatigue tests of NiCo thin films. Procedia Eng. 2011, 10, 1303-1308. [CrossRef]

22. Min, H.-G.; Kang, D.-J.; Park, J.-H. Comparison of Tensile and Fatigue Properties of Copper Thin Film Depending on Process Method. Appl. Sci. 2020, 10, 388. [CrossRef]

23. Petersen, K.E. Silicon as a mechanical material. Proc. IEEE 1982, 70, 420-457. [CrossRef]

24. Matula, R.A. Electrical resistivity of copper, gold, palladium, and silver. J. Phys. Chem. Ref. Data 1979, 8, 1147-1298. [CrossRef]

25. Takahashi, Y.; Akiyama, H. Heat capacity of gold from 80 to 1000 K. Thermochim. Acta 1986, 109, 105-109. [CrossRef]

26. Raja, M.M.; Gambino, R.; Sampath, S.; Greenlaw, R. Thermal Sprayed Thick-Film Anisotropic Magnetoresistive Sensors. IEEE Trans. Magn. 2004, 40, 2685-2687. [CrossRef]

27. Jin, K.; Mu, S.; An, K.; Porter, W.; Samolyuk, G.; Stocks, G.; Bei, H. Thermophysical properties of Ni-containing single-phase concentrated solid solution alloys. Mater. Des. 2017, 117, 185-192. [CrossRef] 